\title{
Binding Potential
}

National Cancer Institute

\section{Source}

National Cancer Institute. Binding Potential. NCI Thesaurus. Code C95006.

A quantity used in tracer studies of receptor density in certain biological processes where this binding potential is proportional to the receptor density. Typically such processes involving transmitters and receptors would be modeled for interpreting dynamic scans. 